\title{
Cooperative C-O Bond Activation by a Heterobinuclear Al-Fe Com- plex Operating by a Radical Pair Mechanism
}

\author{
Soumen Sinhababu ${ }^{\dagger}$, Maxim R. Radzhabov ${ }^{\dagger}$, and Neal P. Mankad* \\ Department of Chemistry, University of Illinois at Chicago, 845 W. Taylor St., Chicago, Illinois 60607, United States
}

\begin{abstract}
Activation of inert molecules like $\mathrm{CO}_{2}$ is often mediated by cooperative chemistry between two reactive sites within a catalytic assembly, the most common form of which is Lewis acid/base bifunctionality observed in both natural metalloenzymes and synthetic systems. Here, we disclose a heterobinuclear complex with an Al-Fe bond that instead activates $\mathrm{CO}_{2}$ and other substrates through cooperative behavior of two radical intermediates. The complex L(Me)Al-Fp $\left(2, \mathrm{~L}=\mathrm{HC}\left\{(\mathrm{CMe})\left(2,6-{ }^{i} \mathrm{Pr}_{2} \mathrm{C}_{6} \mathrm{H}_{3} \mathrm{~N}\right)\right\}_{2}, \mathrm{Fp}=\right.$ $\left.\mathrm{FeCp}(\mathrm{CO})_{2}\right)$ was found to insert $\mathrm{CO}_{2}$ and cyclohexene oxide, producing $\mathrm{LAl}(\mathrm{Me})\left(\mu: \kappa_{2}-\mathrm{O}_{2} \mathrm{C}\right) \mathrm{Fp}(3)$ and $\mathrm{LAl}(\mathrm{Me})\left(\mu-\mathrm{OC} \mathrm{H}_{10}\right) \mathrm{Fp}(4)$, respectively. Further atom transfer, decarbonylation, and isomerization reactivity was also observed. Detailed mechanistic studies on the $\mathrm{CO}_{2}$ and epoxide insertion reactions indicate an unusual mechanism in which (i) the Al-Fe bond dissociates homolytically to generate formally $\mathrm{Al}^{\mathrm{II}}$ and $\mathrm{Fe}^{\mathrm{I}}$ metalloradicals, then (ii) the metalloradicals add to substrate in a pairwise fashion initiated by $\mathrm{O}$ coordination to Al. The accessibility of this unusual mechanism is aided, in part, by the redox non-innocent nature of $\mathrm{L}$ that stabilizes formally $\mathrm{Al}^{\mathrm{II}}$ intermediates with predominantly $\mathrm{Al}^{\mathrm{III}}$-like character. This "radical pair" pathway represents an unprecedented mechanism for $\mathrm{CO}_{2}$ activation.
\end{abstract}

\section{INTRODUCTION}

Identifying new reaction pathways for activation of inert substrates enables rational design of catalysts for challenging synthetic transformations. Although historically the activation of inert substrates by coordination complexes has focused on unsaturated mononuclear systems with single-site reactivity, recently there has been a resurgence in cooperative bond activation studies in which reactivity is delocalized over two or more reactive sites within a well-defined system. Examples include frustrated Lewis pairs (FLPs), ${ }^{1}$ metal-ligand bifunctional catalysts, ${ }^{2}$ homo- and heterobinuclear metal complexes, ${ }^{3}$ and multinuclear metal clusters. ${ }^{4}$ As a representative example, one can consider the coordination chemistry of $\mathrm{CO}_{2}$. While $\mathrm{CO}_{2}$ activation by mononuclear metal complexes has been mapped extensively, ${ }^{5}$ remaining challenges in catalytic $\mathrm{CO}_{2}$ fixation have motivated numerous studies on cooperative $\mathrm{CO}_{2}$ activation. ${ }^{6}$ The dominant paradigm is one of Lewis acid/base bifunctionality (Figure 1a): a Lewis basic reactive site adds a reactive electron pair to the carbon center of $\mathrm{CO}_{2}$, while the resultant buildup of negative charge on oxygen is simultaneously stabilized by a Lewis acidic reactive site. ${ }^{7}$ Since the seminal work of Floriani on cooperative $\mathrm{CO}_{2}$ activation by low-valent $\mathrm{Co} / \mathrm{M}$ bifunctional systems ( $\mathrm{M}=$ alkali metal $),{ }^{8}$ numerous examples of metal- and non-metal-based systems functioning by this paradigm have been identified. ${ }^{9}$ Moreover, Lewis acid/base bifunctionality is thought to be the operative paradigm in nature, stabilizing $\mathrm{CO}_{2-}$ activated intermediates in both aerobic $(\mathrm{Mo} / \mathrm{Cu})$ and anaerobic $(\mathrm{Ni} / \mathrm{Fe})$ carbon monoxide dehydrogenase enzymes. ${ }^{10}$ Identifying reaction pathways beyond this prevailing $\mathrm{CO}_{2}$ activation manifold has the potential to open new catalyst design strategies. $^{11}$

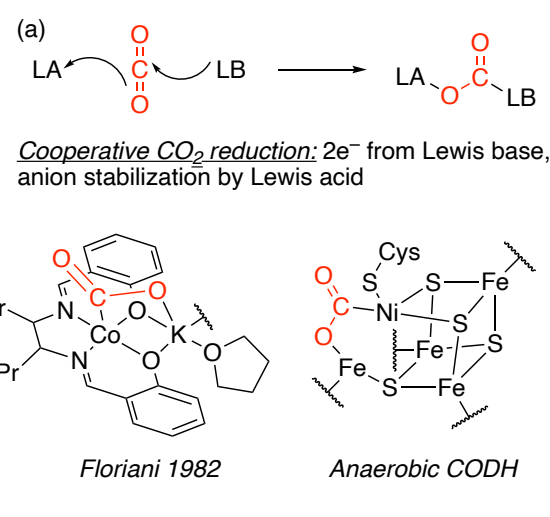

(b)
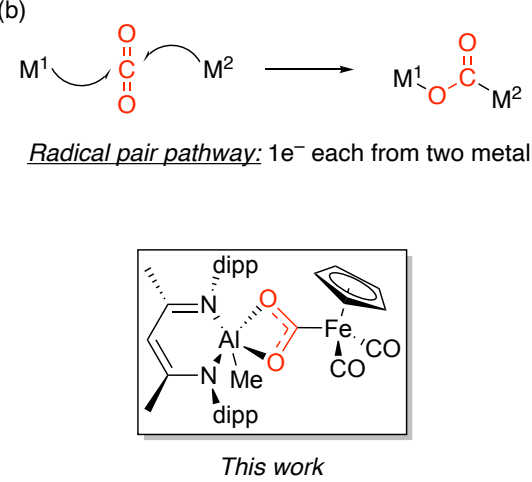

Figure 1. Cooperative $\mathrm{CO}_{2}$ activation pathways and representative examples: (a) Lewis acid/base bifunctionality, (b) radical pair chemistry (this work).

In this report, we disclose a system that activates $\mathrm{CO}_{2}$ and other substrates by a radical pair mechanism, which is a novel mechanistic paradigm for cooperative $\mathrm{CO}_{2}$ reactivity (Figure 
1b). In our discovered system, a heterobinuclear complex dissociates homolytically to generate two metalloradical intermediates, which then cooperatively activate $\mathrm{CO}_{2}$ as a radical pair that donates one electron per metal. Activation of $\mathrm{CO}_{2}$ by a metalloradical pair is quite rare, and typically generation of the radical pair in those cases requires photochemical or electrochemical activation of a precursor complex. ${ }^{12 \mathrm{a}}$ The concept of frustrated radical pairs has recently emerged in the field of FLP chemistry, ${ }^{12 \mathrm{~b}-\mathrm{d}}$ but typically such systems are limited to activation of relatively weak bonds (e.g. H-SnR 3 , RO-OR) or substrates possessing radical character of their own (e.g. $\mathrm{O}_{2}$, TEMPO). On the contrary, here the heterobimetallic radical pair is capable of cooperatively activating not only $\mathrm{CO}_{2}$ but also the $\mathrm{C}-\mathrm{O}$ bond of an epoxide as well as $\mathrm{S}_{8}$ and $\mathrm{Me}_{3} \mathrm{Si}_{-} \mathrm{N}_{3}$, all under ambient conditions with no external stimulus.
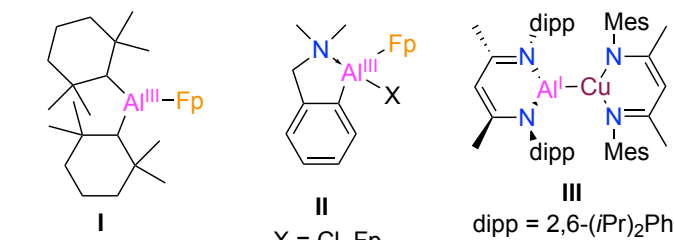

II

$\mathrm{Fp}=\left(\mathrm{C}_{5} \mathrm{H}_{5}\right) \mathrm{Fe}(\mathrm{CO})_{2}$

$\mathrm{X}=\mathrm{Cl}, \mathrm{Fp}$

III

$\operatorname{dipp}=2,6-(\text { iPr })_{2} \mathrm{Ph}$; Mes $=2,4,6-(\mathrm{Me})_{3} \mathrm{Ph}$

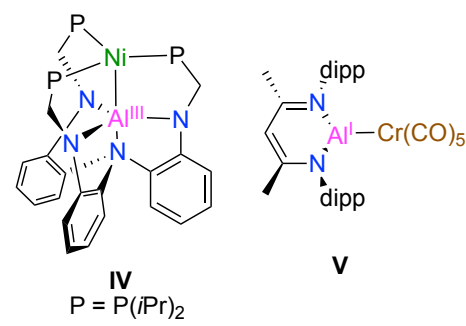

Figure 2. Previous examples of heterobimetallic $\mathrm{Al}^{\mathrm{I}}-\mathrm{M}$ or $\mathrm{Al}^{\mathrm{III}}-\mathrm{M}$ complexes $(\mathrm{M}=$ earth abundant transition metal).

As detailed below, our discovery emerged from studies of an Al-Fe heterobinuclear system. Despite extensive recent work on heterobimetallic chemistry, ${ }^{13}$ heterobimetallic complexes combining main group and transition metals are rare in comparison to such complexes pairing two transition metals. Aluminum is the most abundant metal in earth's crust (7.4\%) and finds use in many catalytic transformations. ${ }^{14}$ However, heterobimetallic complexes bearing aluminum are not thoroughly studied and their reactivity remains underexplored, ${ }^{15}$ especially for heterobimetallic complexes in which aluminum is paired with another earth-abundant metal. The Nöth and Braunschweig groups synthesized $\mathrm{Al}^{\mathrm{III}}$-Fe heterobimetallic complexes (I and II; Figure 2 ), but no reactivity was reported. ${ }^{16,17}$ Very recently, the Power group reported synthesis of an $\mathrm{Al}^{\mathrm{I}}-\mathrm{Cu}$ heterobimetallic species (III). ${ }^{18}$ Hill, McMullin, and coworkers also prepared $\mathrm{Al}^{\mathrm{I}}-\mathrm{Cu}$ heterobimetallic complexes and explored their reactivity with $\mathrm{CO}_{2}$ and carbodiimides. ${ }^{19}$ The Lu group prepared a coordination complex containing $\mathrm{Ni}$ and $\mathrm{Al}^{\mathrm{III}}(\mathrm{IV}){ }^{20}$ The Crimmin group synthesized $\mathrm{Cr}-\mathrm{Al}^{\mathrm{I}}$ complex from the reaction of $\mathrm{Al}(\mathrm{I})$ and $\mathrm{Cr}(\mathrm{CO})_{6} \cdot{ }^{21}(\mathrm{~V})$, although no reactivity was reported.

We became interested in pursuing the chemistry of $\mathrm{Al}^{\mathrm{III}}-\mathrm{Fe}$ complexes. Despite aluminum and iron being the two most abundant metals in earth's crust ( $7.4 \%$ and $5 \%$, respectively), only a few $\mathrm{Al}^{\mathrm{III}}$-Fe heterobimetallic complexes have been reported but their reactivity has never been studied. ${ }^{16,17,22}$ Herein we report that the $\mathrm{Al}^{\mathrm{III}}$-Fe heterobimetallic complex, L(Me)Al$\mathrm{FeCp}(\mathrm{CO})_{2}\left(\mathrm{~L}=\mathrm{HC}\left\{(\mathrm{CMe})\left(2,6-i-\mathrm{Pr}_{2} \mathrm{C}_{6} \mathrm{H}_{3} \mathrm{~N}\right)\right\}_{2}\right)$, is able to insert $\mathrm{CO}_{2}$ and cyclohexene oxide as well as undergo atom transfer reactions. Moreover, photochemical decarbonylation and isomerization pathways are also reported. All the new complexes were structurally characterized. Using a combined experimental/computational approach, the reaction pathways for $\mathrm{CO}_{2}$ activation and epoxide ring opening were elucidated to involve (i) homolytic dissociation to formally $\mathrm{Al}^{\mathrm{II}}$ and $\mathrm{Fe}^{\mathrm{I}}$ metalloradicals, then (ii) pairwise addition to substrate prior to solvent cage escape. This "radical pair" mechanism is a novel mode of cooperative $\mathrm{CO}_{2}$ activation.

\section{RESULTS \& DISCUSSION}

Synthesis and thermal reactivity. To synthesize $\mathrm{Al}^{\mathrm{III}}-\mathrm{Fe}$ heterobimetallic complex $\mathrm{LAl}(\mathrm{Me}) \mathrm{Fp}\left(\mathbf{2}, \mathrm{Fp}=\mathrm{FeCp}(\mathrm{CO})_{2}\right)$, reaction of $\mathrm{LAl}(\mathrm{Me}) \mathrm{I}(\mathbf{1})$ was carried out with $\mathrm{KFp}$ in a mixture of toluene and ether for $16 \mathrm{~h}$. Compound 2 was obtained as a colorless solid in moderate yield $(66 \%)$ and was found to be soluble in toluene and diethyl ether but to decompose in tetrahydrofuran, chloroform, and dichloromethane.

Reactions of 2 with $\mathrm{CO}_{2}$ and epoxide were carried out since they are useful feedstock for preparation of cyclic or polycarbonate products, often with the involvement of $\mathrm{Al}$ catalysts. ${ }^{23}$ Accordingly, reaction of compound 2 with $\mathrm{CO}_{2}$ in toluene resulted $\mathrm{CO}_{2}$-inserted product $\mathrm{LAl}(\mathrm{Me})\left(\mu: \kappa_{2}-\mathrm{O}_{2} \mathrm{C}\right) \mathrm{Fp}(\mathbf{3})$ as a colorless solid in $81 \%$ yield (Scheme 1). Insertion of $\mathrm{CO}_{2}$ into Al$\mathrm{M}$ bonds with $\kappa_{2}$ binding to $\mathrm{Al}$ is rare, with previously reported examples involving low valent $\mathrm{Al}^{\mathrm{I}}-\mathrm{Au}$ and $\mathrm{Al}^{\mathrm{I}}-\mathrm{Cu}$ complexes rather than $\mathrm{Al}^{\mathrm{III}}$ species. ${ }^{19,24}$ Compound $\mathbf{3}$ was stable under heat and vacuum, and we observed no evidence for conversion back to 2 under these conditions. In the ${ }^{13} \mathrm{C}\left\{{ }^{1} \mathrm{H}\right\}$ NMR spectrum of 3 , the carbon atom of the $\left[\kappa_{2}-\mathrm{O}_{2} \mathrm{C}\right]$ moiety resonates at 220.8 ppm, which is shifted downfield compared to the bridging $\mathrm{CO}_{2}$ unit in $\left[\mathrm{Cp}_{2} \mathrm{Zr}(\mathrm{Cl})\left(\mu: \kappa_{2}-\mathrm{O}_{2} \mathrm{C}\right) \mathrm{FeCp}(\mathrm{CO})_{2}\right](\delta=212.6 \mathrm{ppm}){ }^{25}$ Stoichiometric reaction of 2 with cyclohexene oxide was carried out at room temperature, resulting in ring-opened product $\mathrm{LAl}(\mathrm{Me})\left(\mu-\mathrm{OC}_{6} \mathrm{H}_{10}\right) \mathrm{Fp}(4,57 \%$, Scheme 1). Ring opening of epoxides using $\mathrm{Al} / \mathrm{Co}$ heterobimetallic catalysts has been proposed by the Coates group for several carbonylation reactions, ${ }^{26}$ but such an intermediate has never been isolated until now. Compound 4 is stable at $-25^{\circ} \mathrm{C}$ but decomposes slowly at room temperature inside the glove box. 

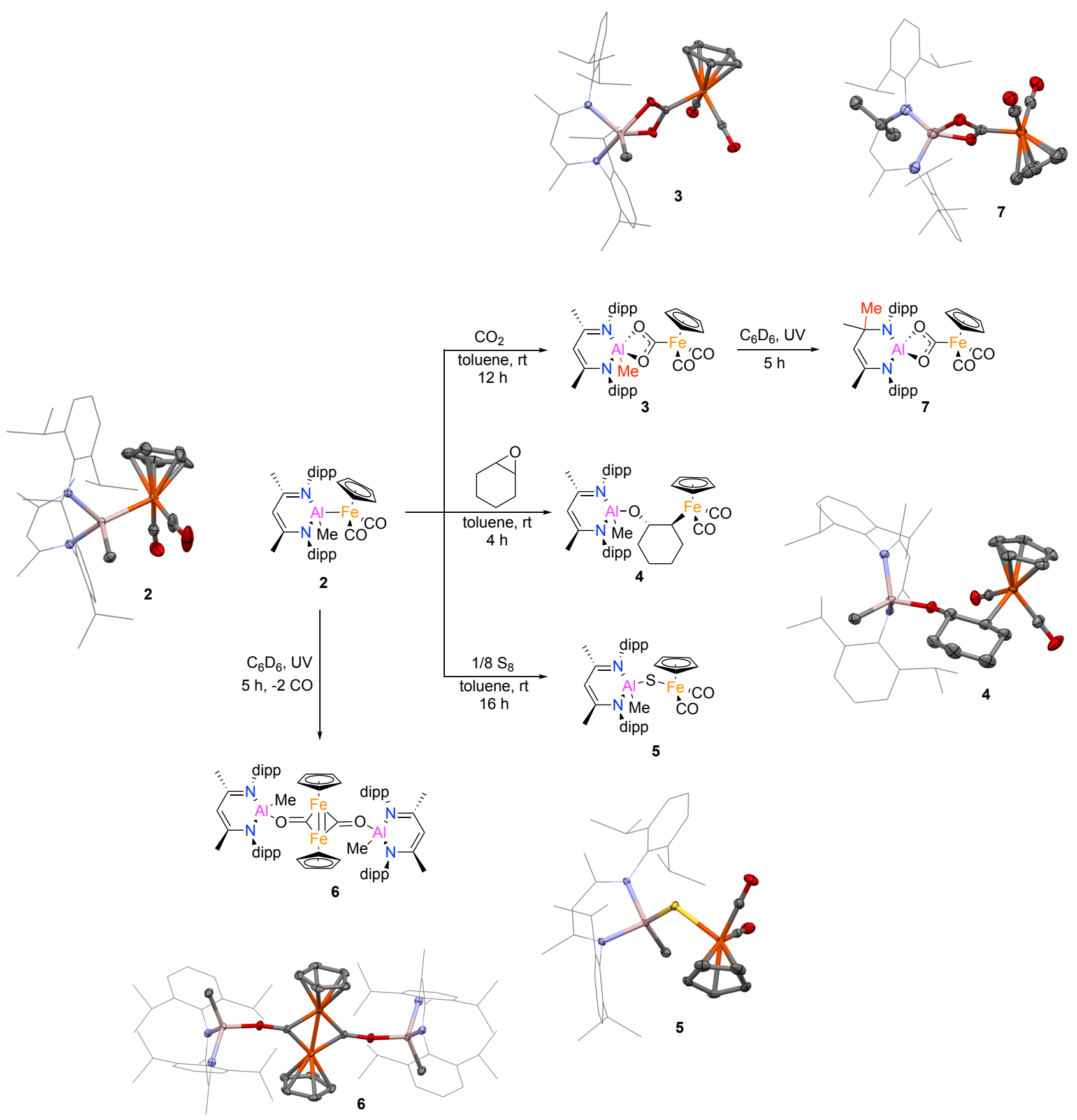

Scheme 1. Thermal and photochemical reactivity studies of an $\mathrm{Al}^{\mathrm{III}}$-Fe heterobinuclear system, including solid-state structures of complexes 2-7 determined by X-ray crystallography. For clarity, hydrogen atoms and co-crystallized solvent molecules are omitted from the crystal structures; ligand backbones (except nitrogen) are shown as wireframes, and all other atoms are shown as $50 \%$ probability ellipsoids.

The molecular structures of $\mathbf{2}$ and $\mathbf{4}$ feature four-coordinate aluminum centers with distorted tetrahedral geometries, while 3 has a penta-coordinate aluminum center with distorted square pyramidal geometry, as determined by X-ray crystallography. The Fe-Al bond length [2.478(9) $\AA$ ] in 2 is comparable to the value of $2.480(1) \AA$ reported for the related compound $\mathrm{LAl}(\mathrm{Cl}) \mathrm{Fp}^{*}\left(\mathrm{Fp}^{*}=\mathrm{Cp} * \mathrm{Fe}(\mathrm{CO})_{2} ; \mathrm{Cp}^{*}=\mathrm{C}_{5} \mathrm{Me}_{5}\right){ }^{22 \mathrm{c}}$ The $\mathrm{Al}-\mathrm{O}$ bond lengths in 3 [1.980(1) and 1.897(1) $\AA$ ] are slightly longer to the corresponding bonds $[1.880(5)$ and 1.861(4) $\AA]$ present in $(\mathrm{NON}) \mathrm{Al}\left(\kappa_{2}-\mathrm{O}_{2} \mathrm{C}\right) \mathrm{AuP}^{t} \mathrm{Bu}_{3}(\mathrm{NON}=4,5$-bis(2,6-diisopropylanilido)-2,7-di-tert-butyl-9,9-dimethylxanthene) reported by the Aldridge group, ${ }^{24}$ possibly due to the different aluminum oxidation states. The $\mathrm{O}-\mathrm{C}$ bond lengths for the $\mathrm{Al}\left(\kappa_{2}-\mathrm{O}_{2} \mathrm{C}\right) \mathrm{Fe}$ unit in 3 [1.271(2) and 1.298(2) $\AA$ ] fall between the typical ranges for $\mathrm{C}-\mathrm{O}$ single and double bonds. The $\mathrm{Fe}-\mathrm{C}$ bond [1.933(1) $\AA]$ of the $\mathrm{Al}\left(\kappa_{2}-\mathrm{O}_{2} \mathrm{C}\right) \mathrm{Fe}$ unit is considerably longer than the $\mathrm{Fe}-\mathrm{C}$ bond $[1.87(1) \quad \AA]$ seen in $\mathrm{Ph}_{3} \mathrm{Sn}\left(\kappa_{2}-\right.$ $\left.\mathrm{O}_{2} \mathrm{C}\right) \mathrm{FeCl}(\text { depe })_{2}$ (depe $=1,2$-bis(diethylphosphino)ethane $){ }^{27}$ The molecular structure of $\mathbf{4}$ reveals that $\mathrm{LAl}(\mathrm{Me}) \mathrm{O}$ and Fp moieties are in trans orientation about the cyclohexane unit. The Al-O bond length $[1.728(2) \AA]$ is quite shorter than those 
in compound 3. The Fe- $\mathrm{C}_{\mathrm{Cy}}$ bond length is 2.111(3) $\AA$, which is in range of reported $\mathrm{Fe}-\mathrm{C}_{\text {alkyl }}$ bonds. ${ }^{28}$

Complex 2 was also found to do sulfur atom abstraction from elemental sulfur, giving product 5 in which sulfur inserted into the Al-Fe bond (64\%, Scheme 1). As expected, the Al-S bond length in 5 determined by X-ray crystallography [2.2005(7) $\AA$ ] is longer than the $\mathrm{Al}=\mathrm{S}$ bond length [2.104(1) $\AA$ ] present in $\left.\mathrm{LAl}=\mathrm{S}(\mathrm{NHC})\left(\mathrm{NHC}=\left[\left\{\left(\mathrm{CH}_{2}\right) \mathrm{CN}\left({ }^{i} \mathrm{Pr}\right)\right\}_{2} \mathrm{C}\right]\right)\right)^{29}$ but close to Al$\mathrm{S}$ single bonds in $\left[\mathrm{LAl}(\mu-\mathrm{S})_{2} \mathrm{TiCp}_{2}\right](2.208(1)$ and 2.197(1) $\AA){ }^{30}$ The Fe-S bond distance $(2.3161(8) \AA$ ) is in the range of those reported in related organoiron-sulfur complexes (2.26-2.35 A). ${ }^{31}$

Photochemical reactivity: Complexes $\mathbf{2}$ and $\mathbf{3}$ are stable thermally (up to $60{ }^{\circ} \mathrm{C}$ ) in $\mathrm{C}_{6} \mathrm{D}_{6}$ for at least for $12 \mathrm{~h}$ but were found to react further upon irradiation with UV light. Irradiation of a $\mathrm{C}_{6} \mathrm{D}_{6}$ solution of $\mathbf{2}$ for $5 \mathrm{~h}$ at room temperature resulted in yellow crystals of new complex 6 in low yield (Scheme 1). The solid-state IR spectrum of $\mathbf{6}$ does not show any intense bands in the $2100-1800 \mathrm{~cm}^{-1}$ region characteristic of terminal carbonyl groups, but a new band indicative of bridging carbonyl groups was observed at $1524 \mathrm{~cm}^{-1}$. Due to poor solubility in common organic solvents, we could not characterize complex $\mathbf{6}$ in the solution state, but the identity of the product was confirmed by single-crystal XRD studies. The molecular structure consists of two $[\mathrm{LAl}(\mathrm{Me})]$ and one $\left[(\mathrm{CpFeCO})_{2}\right]$ motifs. It is worth mentioning here that the $\left[(\mathrm{CpFeCO})_{2}\right]$ motif was not characterized structurally in any complex to date, despite the long history of $\left[\mathrm{CpFe}(\mathrm{CO})_{2}\right]_{2}$ chemistry. ${ }^{32}$ The $\mathrm{Fe}-\mathrm{Fe}$ distance in $\mathbf{6}$ is 2.3543(5) $\AA$, which is significantly shorter than the Fe-Fe single bond of the classical $\left[\mathrm{Fe}_{2}(\mathrm{CO})_{9}\right][2.523(1) \AA]$ or in $\left[\mathrm{CpFe}(\mathrm{CO})_{2}\right]_{2}$ $[2.5389(3) \AA]$ and thus can be formulated as a $\mathrm{Fe}=\mathrm{Fe}$ double bond. $^{33,34}$ The $\mathrm{C}-\mathrm{O}$ bond length in 6 [1.292(3) $\AA$ ] is longer than the terminal C-O bonds [1.157(4) $\AA$ ] present in 2.

Subsequently, a $\mathrm{C}_{6} \mathrm{D}_{6}$ solution of $\mathbf{3}$ was irradiated at ambient temperature for $5 \mathrm{~h}$. The ${ }^{1} \mathrm{H}$ NMR spectrum reveals complete conversion of 3 to 7 (Scheme 1). In the ${ }^{1} \mathrm{H}$ NMR spectrum of

compound $\mathbf{3}$, the methyl protons bonded to the aluminum center appear as a singlet at $-0.20 \mathrm{ppm}$ but are shifted downfield to $1.71 \mathrm{ppm}$ in 7 , indicating methyl migration from the aluminum center to the ligand backbone. The crystal structure of 7 revealed that its aluminum center is tetra-coordinate with two nitrogen and two oxygen atoms in its immediate environment. It also confirmed that the methyl group migrated from aluminum to the $\beta$-diketiminate backbone as anticipated from ${ }^{1} \mathrm{H}$ NMR spectroscopy. The methyl migration to the $\beta$-diketiminate ligand transforms it into a dianionic ligand. Although the $\mathrm{M}-\mathrm{C}$ bond migration phenomenon is common in transition metal $\beta$ diketiminate chemistry, this is first report involving an aluminum $\beta$-diketiminate. ${ }^{35}$ The $\mathrm{C}_{3} \mathrm{~N}_{2} \mathrm{Al}$ six membered ring is puckered with both Al-N bonds being almost equal in distance [1.774(3) $\AA$ and 1.808(3)]. The Al-O bond lengths [1.862(2) $\AA$ and 1.848(2)] are shorter than in $\mathbf{3}$ due to change in coordination number at the aluminum center.

Computational analysis of atomic charges $\&$ bonding. To better understand the origins of reactivity of our $\mathrm{Al}^{\mathrm{III}}$-Fe heterobimetallic complex LAl(Me)Fp (2), we decided to study the charge distribution using $\mathrm{NBO}^{36}$ (Figure S19) and QTAIM ${ }^{37}$ (Figure 3) analysis methods on pre-optimized geometries for complex 2 and, for modelling purposes, its simplified counterparts with methyl (Me) 8 and phenyl $(\mathrm{Ph}) \mathbf{9}$ substituents in place of 2,6-diisopropylphenyl (dipp) in 2. QTAIM charges, being origin-independent ${ }^{38}$ and more "chemically intuitive", are consistent with representation of complexes $\mathbf{2 , 8}$ and $\mathbf{9}$ as featuring strongly polarized covalent $\mathrm{Al}^{\mathrm{III}}-\mathrm{Fe}^{0}$ bonds. For comparison, we also calculated NBO and QTAIM charges for a well-studied heterobimetallic system, ${ }^{39}{ }^{\mathrm{Me}} \mathrm{IMesCuFp} 10$ ( ${ }^{\mathrm{Me}} \mathrm{IM}$ esMes $=1,3$ bis(2,4,6-trimethylphenyl)-4,5-dimethylimidazol-2-ylidene, Figures S19 and 3). Just like for Al-Fe complexes, QTAIM charges are much closer to traditional ideas of valences, with $\mathrm{Cu}$ being in the oxidation state of (almost) one and $\mathrm{Fe}$ being in the oxidation state of zero.
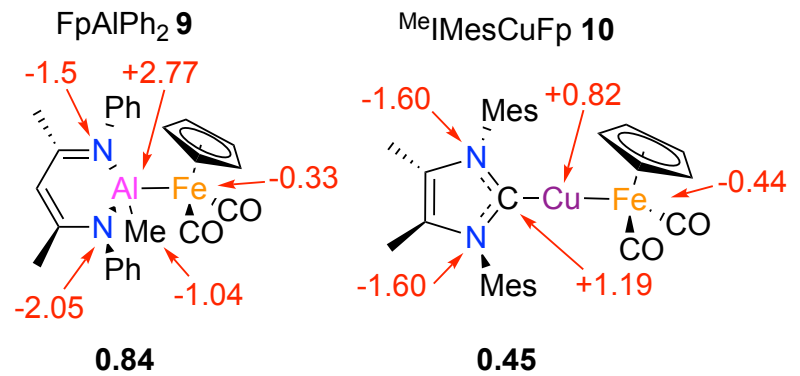

Figure 3. Calculated QTAIM charges for selected atoms in $\mathbf{2}$ and $\mathbf{8 - 1 0}$, with M-Fe Wiberg bond indices indicated below the structures.

To further confirm the presence of the covalent bond between two metals, we calculated Wiberg Bond Indices (WBI) in Löwdin orthogonalized basis ${ }^{40}$ (Figure 3 and Table S1). From the obtained data we can conclude that the Al-Fe bond in $\mathbf{2}$ is almost twice as covalent as the $\mathrm{Cu}-\mathrm{Fe}$ bond in $\mathbf{1 0}$.

Although the used methods gave quite differing charge values, trends between structures in question are consistent. This allowed us to (initially) simplify our model and study Me-substituted complex $\mathbf{8}$ in lieu of complex $\mathbf{2}$ to study its reactivity in silico towards $\mathrm{CO}_{2}$ insertion and epoxide ring opening at a lower computational cost.

Combined computational/experimental investigation of reaction mechanisms. We decided to begin with calculating energies for two dissociation pathways (Scheme 2a), homolytic and heterolytic, for truncated model complexes 8 and 9. However, dissociation energies for both $\mathbf{8}$ and $\mathbf{9}$ proved to be too high, even when including effects of the toluene solvent. It is worth noting that Gibbs free energies and enthalpies are significantly $(>20 \mathrm{kcal} / \mathrm{mol}$ ) lower for homolytic rather than heterolytic dissociation. Steric bulkiness of substituents (i.e. Me vs $\mathrm{Ph}$ ) appeared rather irrelevant: for homolytic dissociation both $\Delta G_{\mathrm{d}}$ and $\Delta H_{\mathrm{d}}$ were just $\sim 6 \mathrm{kcal} / \mathrm{mol}$ lower for significantly bulkier $\mathrm{Ph}$ (9), and for heterolytic dissociation Gibbs free energies and enthalpies for $\mathrm{Ph}$ were even higher than for $\mathrm{Me}(\mathbf{8})$. Therefore, we decided not to proceed with dissociation calculations 
for complex $2(\mathrm{R}=\operatorname{dipp})$, a decision that later proved impru-

dent.

(a)
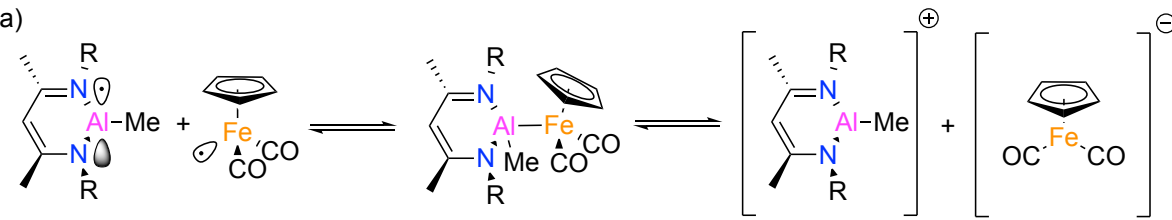

$\begin{aligned} \Delta G_{\mathrm{d}} & \left.=\frac{\text { Homolytic dissociation }}{+48.3 \mathrm{kcal} / \mathrm{mol} \text { for } 8(\mathrm{R}}=\mathrm{Me}\right) \\ \Delta \mathrm{Gd} & =+42.5 \mathrm{kcal} / \mathrm{mol} \text { for } 9(\mathrm{R}=\mathrm{Ph})\end{aligned}$

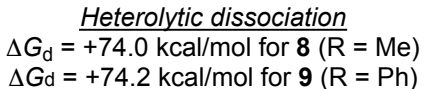

(b)

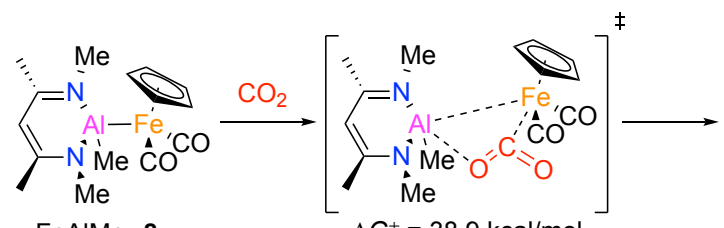

$\mathrm{FpAlMe}_{2} 8$

$\Delta G^{*}=38.9 \mathrm{kcal} / \mathrm{mol}$
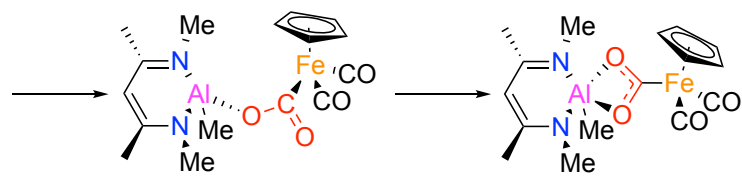

$\mathrm{FpCO}^{-O}-\mathrm{AlMe}_{2} 11$

$\mathrm{Fp}\left(\mathrm{CO}_{2}\right) \mathrm{AlMe}_{2} 12$

$\Delta G_{\mathrm{r} 1}=-1.9 \mathrm{kcal} / \mathrm{mol}$

$\Delta G_{\mathrm{r} 2}=-3.6 \mathrm{kcal} / \mathrm{mol}$

Scheme 2. Unscaled Gibbs free energies (PBE1PBE) for (a) Al-Fe bond dissociation and (b) concerted $\mathrm{CO}_{2}$ insertion pathways.

Since calculated dissociation energies turned out to be too high for reactions that occur readily at ambient conditions, we decided to explore possible mechanistic pathways beginning with the concerted $\mathrm{CO}_{2}$ insertion (Scheme $2 \mathrm{~b}$ ) via the corresponding transition state (TS). Obtained Gibbs free energies (all relative to 8) indicated that while the $\mathrm{CO}_{2}$ insertion per se is thermodynamically favorable, the concerted pathway's high activation barrier is inconsistent with a reaction that occurs with reasonable rate at room temperature, which is what was observed experimentally. To make sure the obtained TS energy was not some sort of a functional artifact, we recalculated the transition state energy using several DFT functionals (Figure $\mathrm{S} 16)$, as well as the TS energy of $\mathrm{CO}_{2}$ insertion for complex 9. Obtained Gibbs free energies are generally consistent among all employed functionals, which indicates that such a high obtained value is not an error of the chosen functional.

However, it is commonly accepted ${ }^{41}$ that translational entropies for reactions in solution should be corrected (scaled) since the loss of molar entropy when two or more molecules in solution interact is not accounted by solvation free energies. Thus, we applied one of the most used correction methods, ${ }^{42}$ which effectively calls for neglecting the contribution of translational entropy altogether. Since such an approach introduces an unknown degree of uncertainty to the Gibbs energies, we limited ourselves only to qualitative comparison of the calculated activation barriers. The scaled TS Gibbs energies (Figure S16) were found to be in the desired range $(\sim 25 \pm 1 \mathrm{kcal} / \mathrm{mol})$ for some functionals. Nevertheless, the activation barrier for this reaction would be higher since the real translational entropy term is not zero.

To gain additional insights on the mechanism, we next conducted an Eyring analysis by obtaining experimental, pseudo- first order (excess $\mathrm{CO}_{2}$ ) rate constants for $\mathrm{CO}_{2}$ activation by 2 across the temperature range 263-303 K (Figure 4). Fitting the data to the Eyring equation provided the experimentally determined activation parameters for $\mathrm{CO}_{2}$ insertion by complex 2: $\Delta H^{\ddagger}=24.9 \mathrm{kcal} / \mathrm{mol}, \Delta S^{\ddagger}=20.5 \mathrm{kcal} / \mathrm{mol}^{*} \mathrm{~K}, \Delta G^{\ddagger} 298 \mathrm{~K}=18.8$ $\mathrm{kcal} / \mathrm{mol}$. The activation entropy for this reaction is large and positive, which indicates a dissociative rate-determining step and is therefore inconsistent with the concerted mechanism shown in Scheme $2 \mathrm{~b}$ (which should give $\Delta S^{\ddagger}<0$ ). Moreover, the trans-stereochemistry of the ring-opened product 4 evident by X-ray crystallography indicates anti-addition of the two metals to the epoxide and thus also testifies against any similar concerted mechanisms.

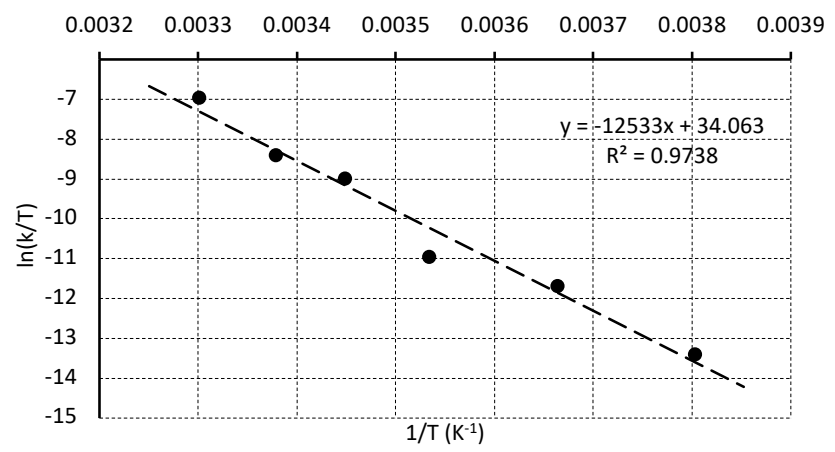

Figure 4. Eyring analysis to extract activation parameters for the $\mathrm{CO}_{2}$ activation reaction by 2 .

With these considerations in mind, we decided to revisit the dissociation pathways, this time with the model for $\mathbf{2}$ with fullsized dipp-substituted ligands (Scheme 3 ). To our surprise, the dissociation Gibbs free energies and enthalpies were $\sim 15$ 
$\mathrm{kcal} / \mathrm{mol}$ lower than for closest counterpart 9. This brought the activation barrier down, closer to the experimental value and within the expected range for a room-temperature reaction. Therefore, relying on models with truncated substituents, a common approach in computational organometallic chemistry, is not always justified. It is curious that addition of just two isopropyl groups to each phenyl ring had such drastic effect on dissociation energies, which we attribute solely to significantly higher steric tension in complex $\mathbf{2}$ relative to $\mathbf{8}$ and $\mathbf{9}$, given their similar electronic structures. Collectively, these observations also reinforce the critical importance of calibrating computed mechanisms with experimental (preferably kinetics) data.

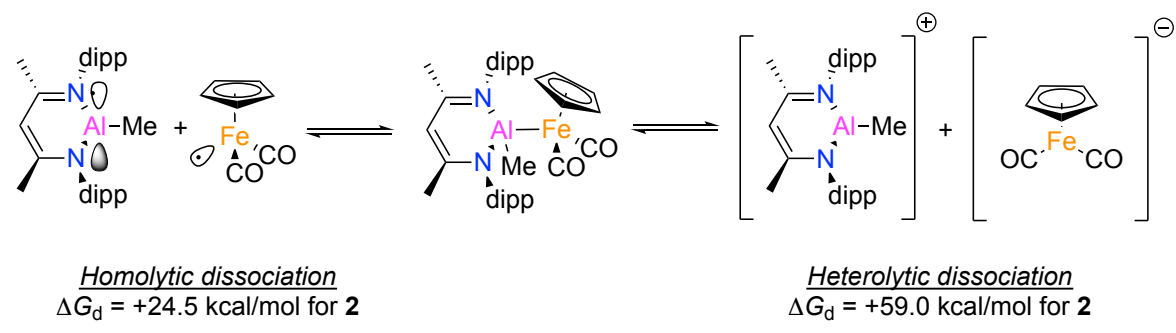

Scheme 3. Gibbs free energies (PBE1PBE) for Al-Fe bond dissociation of 2;

With more evidence towards homolytic dissociation of complex 2 as the origin of its reactivity and having ruled out several alternatives (Figure S18), we calculated the Gibbs free energies of interactions of both $\mathrm{Al}$ and $\mathrm{Fe}$ metalloradicals with both $\mathrm{CO}_{2}$ and cyclohexene oxide. As follows from the obtained Gibbs energies, it is clear that both $\mathrm{CO}_{2}$ and cyclohexene oxide prefer to react with the $\mathrm{Al}$ radical $13\left(\mathrm{Al}(\operatorname{dipp})_{2}\right)$ first rather than with $\mathrm{Fe}$ radical $14(\mathrm{Fp})$, as indicated in Scheme 4. In the first case, for $\mathrm{CO}_{2}$ insertion, we could not localize a minimum corresponding to the radical $\mathrm{Fe}-\mathrm{CO}_{2}$ complex 15 (however, we were able to localize a minimum for a similar anionic complex, which has been observed experimentally ${ }^{43}$; see SI for more details). Instead, the localized minimum was some sort of a supramolecular complex of Fp radical 14 and $\mathrm{CO}_{2}$, held together by weak non-covalent bonds (as shown by QTAIM diagrams and calculated WBIs; Figure 5a). However, we localized a minimum for the complex 16 where a linear $\mathrm{CO}_{2}$ molecule is coordinated on the $\mathrm{Al}$ center of complex 13, giving a quite strong covalent bond (also Figure 5a). Such coordination is endothermic, but the subsequent interception of Fp radical 14 makes $\mathrm{CO}_{2}$ insertion a thermodynamically favorable process.

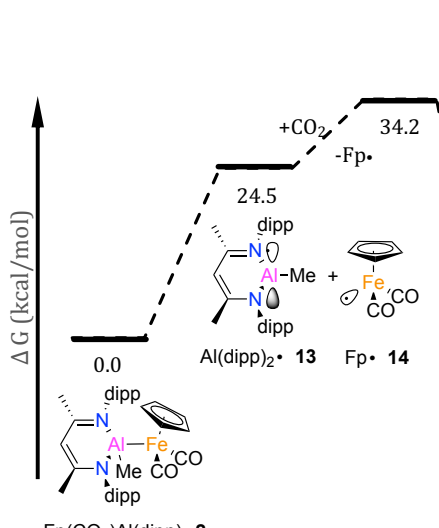

$\mathrm{Fp}\left(\mathrm{CO}_{2}\right) \mathrm{Al}(\text { dipp })_{2} 2$

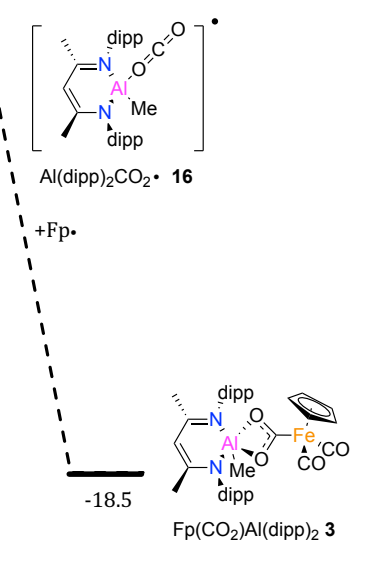

Scheme 4. Gibbs free energy diagram for calculated pathways of $\mathrm{CO}_{2}$ activation mediated by 2 .

Epoxide ring opening is also an exothermic process even for initiation with the $\mathrm{Al}$ radical 13 , while initiation by Fe radical 14 has a very high barrier (Scheme 5). Subsequent recombination of Al-epoxide complex 18 with Fp 14 to give the observed product $\mathbf{4}$ is energetically very favorable.

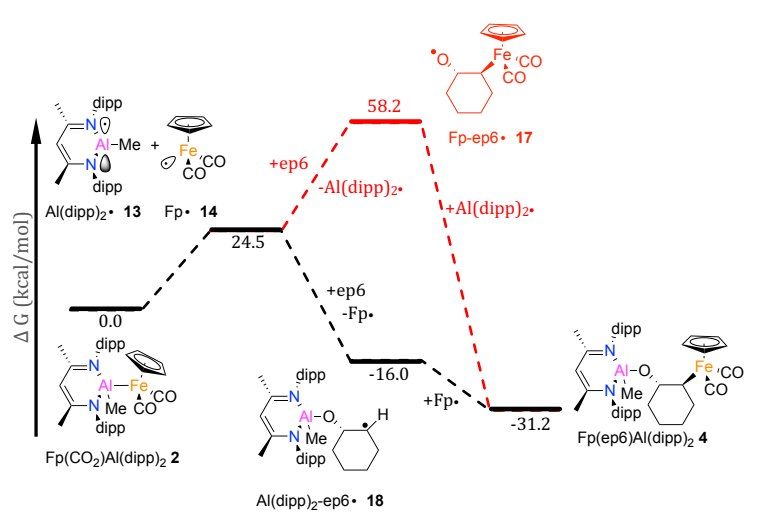

Scheme 5. Gibbs free energy diagrams for calculated pathways of cyclohexene oxide ring opening mediated by 2 .

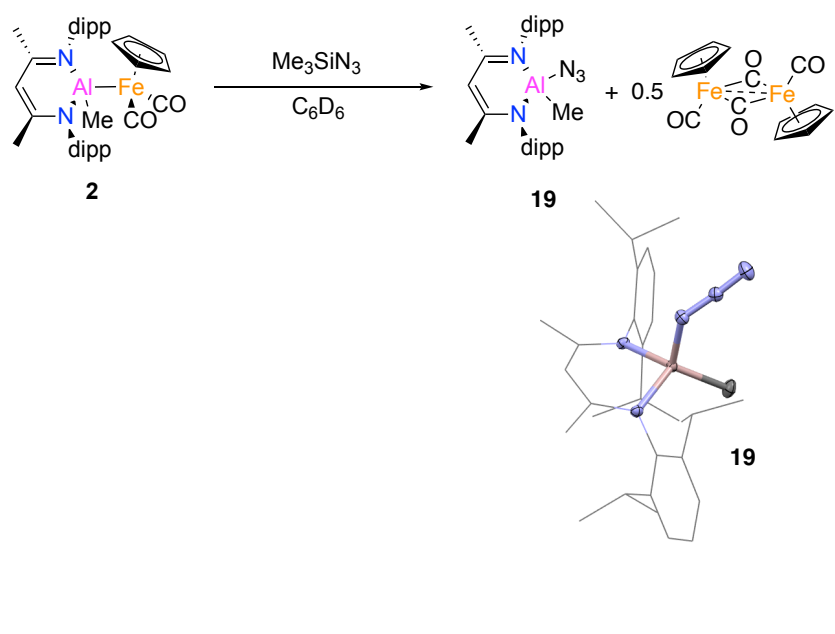

Scheme 6. Reaction of $\mathbf{2}$ and $\mathrm{Me}_{3} \mathrm{SiN}_{3}$, including solid-state structures of complex 19 determined by X-ray crystallography. For clarity, hydrogen atoms and co-crystallized solvent molecules are omitted from the crystal structures; ligand backbones (except nitrogen) are shown as wireframes, and all other atoms are shown as $50 \%$ probability ellipsoids.

The identification of the O-bound $\mathrm{CO}_{2}$ adduct $\mathbf{1 6}$ along the reaction pathway is notable, as this coordination mode has rarely been observed experimentally ${ }^{44}$ and is typically proposed 
during (1-electron) reductive coupling of $\mathrm{CO}_{2}$ to form oxalate ${ }^{45}$ (rather than for 2-electron $\mathrm{CO}_{2}$ reduction). Moreover, it is a rare example of a formally $\mathrm{Al}^{\mathrm{II}}$ species playing an important role in reactivity. ${ }^{46}$ Thus, we chose to analyze the electronic structure of 16 and its precursor complex 13 further. Calculated Mulliken spin densities for selected atoms (Figure 5b) of these complexes indicate that the unpaired electron is mostly delocalized through the conjugated $\beta$-diketiminate ligand but not on $\mathrm{Al}$ itself for either complex, nor on the $\mathrm{CO}_{2}$ moiety in the case of 16. In other words, although 13 is formally a $\left[\left(\mathrm{L}^{-}\right) \mathrm{Al}^{\mathrm{II}}(\mathrm{Me})\right]$ species, it is perhaps better formulated as $\left[\left(\mathrm{L}^{\cdot 2-}\right) \mathrm{Al}^{\mathrm{III}}(\mathrm{Me})\right]$ and thus possess a vacant Al-centered $3 p_{z}$ orbital for substrate coordination.
Given these computational results indicating an unusual radical-pair mechanism for the cooperative bond activation chemistry of 2, we sought experimental evidence for formation of metalloradicals 13 and/or 14 under relevant conditions. One observation we can report is the reaction of $\mathbf{2}$ with excess $\mathrm{Me}_{3} \mathrm{SiN}_{3}$, which resulted $\mathrm{LAl}(\mathrm{Me}) \mathrm{N}_{3}(\mathbf{1 9})$ and $\mathrm{Fp}_{2}$ as major products (Scheme 6). The formation of $\mathrm{Fp}_{2}$ as the dominant $\mathrm{Fe}$ containing product in this reaction can be viewed as experimental validation of metalloradical 14 forming in situ. Further evaluation of the radical-pair reactivity of $\mathbf{2}$ is currently underway in our laboratory. (a)

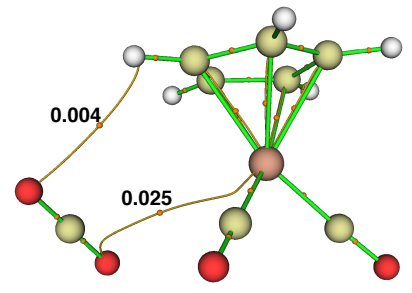

$\left[\mathrm{Fp} \cdot \mathrm{CO}_{2}\right] ' 15$

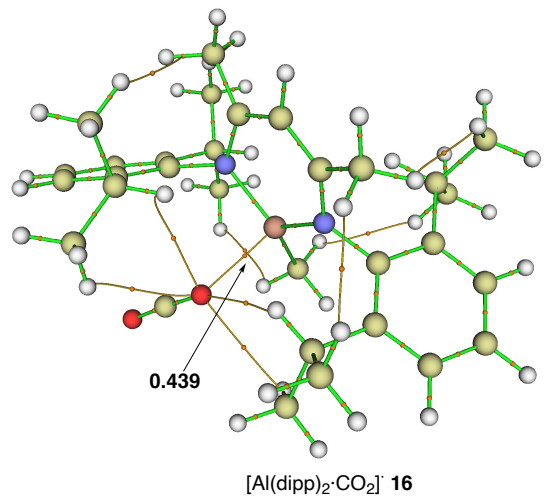

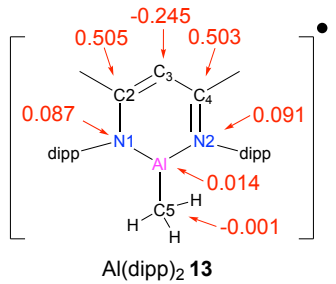
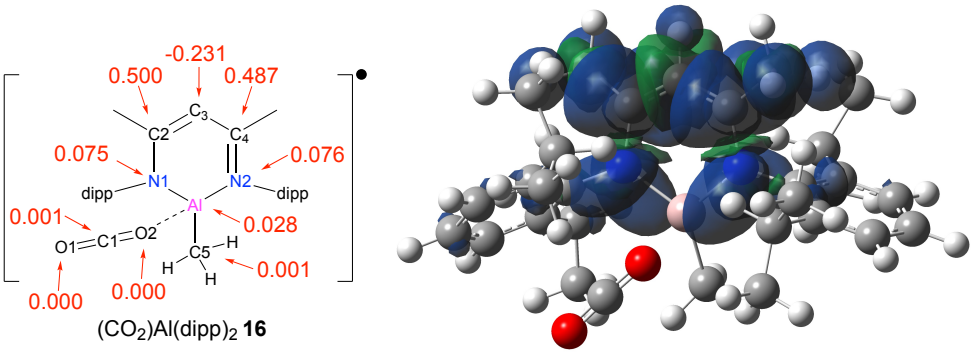

Figure 5. (a) Selected QTAIM paths connecting $(3,-3)$ and $(3,-1)$ critical points for $\mathbf{1 5}$ and $\mathbf{1 6}$ with key all-electron Wiberg bond indices shown; (b) calculated Mulliken spin densities for selected atoms and corresponding spin density plots for 13 and 16.

\section{CONCLUSIONS}

A series of reactivity studies were carried out on a heterobimetallic Al-Fe complex, 2. Most notably, complex 2 reacts cleanly with $\mathrm{CO}_{2}$ and cyclohexene oxide, giving $\mathrm{CO}_{2}$ inserted product 3 and epoxide ring opening product 4 , respectively. Detailed kinetic and theoretical studies were performed on these two reactions and indicated an unusual radical-pair mechanism in which Al-Fe homolytic dissociation precedes pairwise metalloradical addition to substrate. Particularly novel aspects of this study include:

- Unexpected involvement of formally $\mathrm{Al}^{\mathrm{II}}$ reactive intermediates

- An unprecedented mechanism for $\mathrm{CO}_{2}$ activation

- An instructive interplay between theory and experiment that emphasizes the importance in computational organometallic chemistry of (i) validating calculated reaction pathways with kinetics measurements, and (ii) modeling complete (as opposed to truncated) ligand substituents

\section{METHODS}

Experimental methods. All experimental manipulations were carried out under inert dinitrogen atmosphere using standard Schlenk line and glovebox techniques. All new compounds were characterized by ${ }^{1} \mathrm{H}$ and ${ }^{13} \mathrm{C}\left\{{ }^{1} \mathrm{H}\right\}$ NMR spectroscopy, solid-state IR spectroscopy, and single-crystal X-ray diffraction. Detailed experimental procedures and spectral data are available as Supplementary Information, and supporting crystallographic data in the form of CIF files are available upon request from the Cambridge Crystallographic Data Centre using deposition numbers 2100519-2100525.

Computational methods. Density Functional Theory calculations (at the PBE0 $0^{47 \mathrm{a}}-\mathrm{G} 3 \mathrm{BJ}^{47 \mathrm{~b}} / \mathrm{def} 2-\mathrm{TZVP}^{47 \mathrm{c}}$ level of theory; $\mathrm{SMD}^{47 \mathrm{~d}}$ solvation model with toluene parameters), as implemented in the Gaussian 16 (Revision B.01) ${ }^{48}$ code, were employed to optimize molecular geometries and determine bonding energies, Mulliken spin densities and NBO charges (using NBO version 3.1, ${ }^{49}$ as implemented in Gaussian 16). The opensource MultiWFN ${ }^{50}$ (version 3.8) program was employed to calculate and visualize Wiberg bond indices, QTAIM charges, critical points and paths (using data derived from Gaussian DFT calculations). For more details on comprehensive computational methods please see Supplementary Information. 


\section{Supporting Information}

The Supporting Information is available free of charge on the ACS Publications website.

Experimental procedures, spectral data, computational data (PDF)

\section{AUTHOR INFORMATION}

\section{Corresponding Author}

*npm@uic.edu

\section{Author Contributions}

$\dagger$ These authors contributed equally.

\section{ACKNOWLEDGMENT}

This material is based upon work supported by the U.S. Department of Energy (DOE), Office of Science, Office of Basic Energy Sciences (BES), under Award Number DE-SC0021055. Computational resources and services were provided by the Advanced Cyberinfrastructure for Education and Research (ACER) group at UIC. Instrumentation for X-ray crystallography at UIC was funded, in part, by the National Institutes of Health under grant R01 GM116820. The structure of complex 7 was obtained using NSF's ChemMatCARS Sector 15 supported by the Divisions of Chemistry (CHE) and Materials Research (DMR), National Science Foundation, under grant number NSF/CHE-1834750. Use of the Advanced Photon Source, an Office of Science User Facility operated for the DOE Office of Science by Argonne National Laboratory, was supported by the U.S. DOE under Contract No. DE-AC0206CH11357.

\section{REFERENCES}

(1) Stephan, D. W. The Broadening Reach of Frustrated Lewis Pair Chemistry. Science 2016, 354, 7229.

(2) (a) Gunanathan, C.; Milstein, D. Metal-Ligand Cooperation by Aromatization-Dearomatization: A New Paradigm in Bond Activation and "Green" Catalysis. Acc. Chem. Res. 2011, 44, 588-602. (b) Morris, R. H. Exploiting Metal-Ligand Bifunctional Reactions in the Design of Iron Asymmetric Hydrogenation Catalysts. Acc. Chem. Res. 2015, 48, 1494-1502.

(3) (a) Campos, J. Bimetallic cooperation across the periodic table. Nat. Rev. Chem. 2020, 4, 696-702. (b) Powers, I. G.; Uyeda, C. Metalmetal bonds in catalysis. ACS Catal. 2017, 7, 936-958.

(4) Buchwalter, P.; Rose, J.; Braunstein, P. Multimetallic Catalysis Based on Heterometallic Complexes and Clusters. Chem. Rev. 2015 $115,28-126$.

(5) Paparo, A.; Okuda, J. Carbon Dioxide Complexes: Bonding Modes and Synthetic Methods. Coord. Chem. Rev. 2017, 334, 136-149.

(6) (a) Burkart, M. D.; Hazari, N.; Tway, C. L.; Zeitler, E. L. Opportunities and Challenges for Catalysis in Carbon Dioxide Utilization. ACS Catal. 2019, 9, 7937-7956. (b) Appel, A. M.; Bercaw, J. E.; Bocarsly, A. B.; Dobbek, H.; Dubois, D. L.; Dupuis, M.; Ferry, J. G.; Fujita, E.; Hille, R.; Kenis, P. J. A.Frontiers, Opportunities, and Challenges in Biochemical and Chemical Catalysis of $\mathrm{CO}_{2}$ Fixation. Chem. Rev. 2013, 113, 6621-6658.

(7) Gibson, D. H. The Organometallic Chemistry of Carbon Dioxide. Chem. Rev. 1996, 9, 2063-2095.

(8) (a) Gambarotta, S.; Arena, F.; Floriani, C.; Zanazzi, P. F. Carbon dioxide fixation: bifunctional complexes containing acidic and basic sites working as reversible carriers. J. Am. Chem. Soc. 1982, 104, 50825092. (b) Fachinetti, G.; Floriani, C.; Zanazzi, P. F. Bifunctional activation of carbon dioxide. Synthesis and structure of a reversible carbon dioxide carrier. J. Am. Chem. Soc. 1978, 100, 7405-7407.

(9) (a) Hanna, T. A.; Baranger, A. M.; Bergman, R. G. Reaction of Carbon Dioxide and Heterocumulenes with an Unsymmetrical MetalMetal Bond - Direct Addition of Carbon-Dioxide across a ZirconiumIridium Bond and Stoichiometric Reduction of Carbon Dioxide to
Formate. J. Am. Chem. Soc. 1995, 117, 11363-11364. (b) Krogman, J. P.; Foxman, B. M.; Thomas, C. M. Activation of $\mathrm{CO}_{2}$ by a Heterobimetallic $\mathrm{Zr} / \mathrm{Co}$ Complex. J. Am. Chem. Soc. 2011, 133, 1458214585. (c) Mömming, C. M.; Otten, E.; Kehr, G.; Fröhlich, R.; Grimme, S.; Stephan, D. W.; Erker, G. Reversible Metal-Free Carbon Dioxide Binding by Frustrated Lewis Pairs. Angew. Chem., Int. Ed. 2009, 48, 6643-6646. (d) Schlenker, K.; Christensen, E. G.; Zhanserkeev, A. A.; McDonald, G. R.; Yang, E. L.; Lutz, K. T.; Steele, R. P.; Vanderlinden, R. T.; Saouma, C. T. Role of Ligand-Bound $\mathrm{CO}_{2}$ in the Hydrogenation of $\mathrm{CO}_{2}$ to Formate at a (PNP)Mn Catalyst. ACS Catal. 2021, 11, 8358-8369. (e) Escomel, L.; Del Rosal, I.; Maron, L.; Jeanneau, E.; Veyre, L.; Thieuleux, C.; Camp, C. Strongly Polarized Iridium $\delta^{-}-$Aluminum $\delta+$ Pairs: Unconventional Reactivity Patterns Including $\mathrm{CO}_{2}$ Cooperative Reductive Cleavage. J. Am. Chem. Soc. 2021, 143, 4844-4856.

(10) (a) Dobbek, H.; Svetlitchnyi, V.; Gremer, L.; Huber, R.; Meyer, O. Crystal Structure of a Carbon Monoxide Dehydrogenase Reveals a [Ni-4Fe-5S] Cluster. Science 2001, 293, 1281-1285. (b) Mankad, N. P.; Ghosh, D. Biomimetic Studies of the $\mathrm{Mo} / \mathrm{Cu}$ Active Site of $\mathrm{CO}$ Dehydrogenase. Comprehensive Coordination Chemistry III, 2021, pp 772-789.

(11) Karunananda, M. K.; Mankad, N. P. Cooperative Strategies for Catalytic Hydrogenation of Unsaturated Hydrocarbons. ACS Catal. 2017, 7, 6110-6119.

(12) (a) Agarwal, J.; Fujita, E.; Schaefer, H. F., III; Muckerman, J. T. Mechanisms for $\mathrm{CO}$ Production from $\mathrm{CO}_{2}$ Using Reduced Rhenium Tricarbonyl Catalysts. J. Am. Chem. Soc. 2012, 134, 5180-5186. (b) Liu, L.; Cao, L. L.; Shao, Y.; Ménard, G.; Stephan, D. W. A Radical Mechanism for Frustrated Lewis Pair Reactivity. Chem. 2017, 3, 259267. (c) Dasgupta, A.; Richards, E.; Melen, R. L. Frustrated Radical Pairs: Insights from EPR Spectroscopy. Angew. Chem., Int. Ed. 2021, 60, 53-65. (d) Holtrop, F.; Jupp, A; Slootweg, J. C. Radicals in frustrated Lewis pair chemistry. Springer, Cham, 2021. pp. 361-385.

(13) (a) Charles III, R.M.; Brewster, T.P. $\mathrm{H}_{2}$ and carbon-heteroatom bond activation mediated by polarized heterobimetallic complexes. Coord. Chem. Rev. 2021, 433, 213765. (b) Hicken, A.; White, A. J. P.; Crimmin, M. R. Selective Reduction of $\mathrm{CO}_{2}$ to a Formate Equivalent with Heterobimetallic Gold-Copper Hydride Complexes. Angew. Chem., Int. Ed. 2017, 56, 15127-15130. (c) Mankad, N. P. Selectivity Effects in Bimetallic Catalysis. Chem. - Eur. J. 2016, 22, 5822-5829. (d) Bagherzadeh, S.; Mankad, N. P. Catalyst Control of Selectivity in $\mathrm{CO}_{2}$ Reduction Using a Tunable Heterobimetallic Effect. J. Am. Chem. Soc. 2015, 137, 10898-10901. (e) Chipman, J. A.; Berry, J. F. Paramagnetic Metal-Metal Bonded Heterobimetallic Complexes. Chem. Rev. 2020, 120, 2409-2447. (f) Power, P. P. Main-group elements as transition metals. Nature 2010, 463, 171-177.

(14) Nikonov, G. I. New Tricks for an Old Dog: Aluminum Compounds as Catalysts in Reduction Chemistry. ACS Catal. 2017, 7 , 7257-7266.

(15) (a) Lai, Q.; Bhuvanesh, N.; Ozerov, O. V. Unexpected B/Al Transelementation within a Rh Pincer Complex. J. Am. Chem. Soc. 2020, 142, 20920-20923. (b) Hara, N.; Saito, T.; Semba, K.; Kuriakose, N.; Zheng, H.; Sakaki, S.; Nakao, Y. Rhodium Complexes Bearing PAlP Pincer Ligands. J. Am. Chem. Soc. 2018, 140, 7070-7073. (c) Ekkert, O.; White, A. J. P.; Toms, H.; Crimmin, M. R. Addition of Aluminium, Zinc and Magnesium Hydrides to Rhodium(III). Chem. Sci. 2015, 6, 5617-5622.

(16) Anand, B. N.; Krossing, I.; Nöth, H. Synthesis and X-Ray Crystal Structure of $(\mathrm{Tmp})_{2} \mathrm{Al}-\mathrm{Fe}(\mathrm{Cp})(\mathrm{CO})_{2}$ : An Alanyl-Containing Iron Complex with a Tricoordinated Aluminum Atom. Inorg. Chem. 1997, 36, 1979-1981.

(17) Braunschweig, H.; Müller, J.; Ganter, B. Molecular Structure of $\left[\mathrm{CpFe}(\mathrm{CO})_{2}\right]_{2} \mathrm{AlAr}(\mathrm{Ar}=2-[($ Dimethylamino $)$ methyl $]$ phenyl $): \mathrm{An}$ Alanediyl Complex with Two Fe-Al Bonds. Inorg. Chem. 1996, 35, 7443-7444.

(18) Mears, K. L.; Stennett, C. R.; Taskinen, E. K.; Knapp, C. E.; Carmalt, C. J.; Tuononen, H. M.; Power, P. P. Molecular Complexes Featuring Unsupported Dispersion-Enhanced Aluminum-Copper and Gallium-Copper Bonds. J. Am. Chem. Soc. 2020, 142, 19874-19878. 
(19) Liu, H-Y.; Schwamm, R. J.; Hill, M. S.; Mahon, M. F.; McMullin, C. L.; Rajabi, N. A. Ambiphilic Al-Cu Bonding. Angew. Chem., Int. Ed. 2021, 60, 14390 -14393.

(20) Rudd, P. A.; Liu, S.; Gagliardi, L.; Young, V. G.; Lu, C. C. Metal-Alane Adducts with Zero-Valent Nickel, Cobalt, and Iron. J. Am. Chem. Soc. 2011, 133, 20724-20727. 7817.

(21) Kong, R. Y.; Crimmin, M. R. Dalton Trans., 2021, 50, 7810-

(22) (a) Fischer, R. A.; Priermeier, T. Transition-Metal-Substituted Alanes: Synthesis and Spectroscopic Studies and the Structure of $\left(\eta^{5}-\right.$ $\left.\mathrm{C}_{5} \mathrm{H}_{5}\right)(\mathrm{CO})_{2} \mathrm{Fe}-\mathrm{Al}\left[\left(\mathrm{CH}_{2}\right)_{3} \mathrm{NMe}_{2}\right]\left({ }^{i} \mathrm{Bu}\right)$. Organometallics 1994, 13 , 4306-4314. (b) Jones, C.; Aldridge, S.; Gans-Eichler, T.; Stasch, A. Synthesis and characterisation of complexes of Group 13 metal amidinate heterocycles with the $\mathrm{CpFe}(\mathrm{CO})_{2}$ fragment. Dalton Trans. 2006, 5357-5361. (c) Riddlestone, I. M.; Urbano, J.; Phillips, N.; Kelly, M. J.; Vidovic, D.; Bates, J. I.; Taylor, R.; Aldridge, S. Salt Metathesis for the Synthesis of M-Al and M-H-Al Bonds. Dalton Trans. 2013, 42, 249-258.

(23) Whiteoak, C. J.; Kielland, N.; Laserna, V.; Escudero-Adán, E. C.; Martin, E.; Kleij, A. W. A Powerful Aluminum Catalyst for the Synthesis of Highly Functional Organic Carbonates. J. Am. Chem. Soc. 2013, 135, 1228-1231.

(24) Hicks, J.; Mansikkamäki, A.; Vasko, P.; Goicoechea, J. M.; Aldridge, S. A Nucleophilic Gold Complex. Nat. Chem. 2019, 11, 237241.

(25) Warratz, S.; Postigo, L.; Royo, B. Direct Synthesis of Iron(0) $N$-Heterocyclic Carbene Complexes by Using $\mathrm{Fe}_{3}(\mathrm{CO})_{12}$ and Their Application in Reduction of Carbonyl Groups. Organometallics 2013, 32, 893-897.

(26) Lamb, J. R.; Hubbell, A. K.; MacMillan, S. N.; Coates, G. W. Carbonylative, Catalytic Deoxygenation of 2,3-Disubstituted Epoxides with Inversion of Stereochemistry: An Alternative AlkeneIsomerization Method. J. Am. Chem. Soc. 2020, 142, 80298035 .

(27) Hirano, M.; Akita, M.; Tani, K.; Kumagai, K.; Kasuga, N. C.; Fukuoka, A.; Komiya, S. Activation of Coordinated Carbon Dioxide in $\mathrm{Fe}\left(\mathrm{CO}_{2}\right)(\text { Depe })_{2}$ by Group 14 Electrophiles. Organometallics 1997, 16 4206-4213.

(28) Friedrich, H. B.; Onani, M. O.; Rademeyer, M. Bromopropyldicarbonyl( $\eta^{5}$-pentamethyl-cyclopentadienyl)iron(II). Acta Cryst. E 2004, 60, m551-m553.

(29) Chu, T.; Vyboishchikov, S. F.; Gabidullin, B.; Nikonov, G. I. Oxidative Cleavage of $\mathrm{C}=\mathrm{S}$ and $\mathrm{P}=\mathrm{S}$ Bonds at an AlI Center: Preparation of Terminally Bound Aluminum Sulfides. Angew. Chem. Int. Ed. 2016, 55, 13306-13311.

(30) Jancik, V.; Roesky, H. W.; Neculai, D.; Neculai, A. M.; HerbstIrmer, R. Preparation of $\left[\mathrm{LAl}(\mu-\mathrm{S})_{2} \mathrm{MCp}_{2}\right](\mathrm{M}=\mathrm{Ti}, \mathrm{Zr})$ from the Structurally Characterized Lithium Complexes $\left[\left\{\mathrm{LAl}(\mathrm{SH})\left[\mathrm{SLi}(\mathrm{thf})_{2}\right]\right\}\right]$ and $\left[\left\{\mathrm{LAl}\left[(\mathrm{SLi})_{2}(\mathrm{thf})_{3}\right]\right\}_{2}\right] \cdot 2 \mathrm{THF}$ Angew. Chem., Int. Ed. 2004, 43, 6192-6196.

(31) Ramalakshmi, R.; Maheswari, K.; Sharmila, D.; Paul, A.; Roisnel, T.; Halet, J-F.; Ghosh, S. Reactivity of cyclopentadienyl transition metal(II) complexes with borate ligands: Structural characterization of the toluene-activated molybdenum complex $\left[\mathrm{Cp} * \mathrm{Mo}(\mathrm{CO})_{2}\left(\eta^{3}-\mathrm{CH}_{2} \mathrm{C}_{6} \mathrm{H}_{5}\right)\right]$. Dalton Trans. 2016, 45, 16317-16324.

(32) Bitterwolf, T. E. Photochemistry and Reaction Intermediates of the Bimetallic Group VIII Cyclopentadienyl Metal Carbonyl Compounds, $\left(\eta^{5}-\mathrm{C}_{5} \mathrm{H}_{5}\right)_{2} \mathrm{M}_{2}(\mathrm{CO})_{4}$ and Their Derivatives. Coord. Chem. Rev. 2000, 206-207, 419-450.

(33) Cotton, F. A.; Troup, J. M. Accurate determination of a classic structure in the metal carbonyl field: nonacarbonyldi-iron. J. Chem. Soc., Dalton Trans. 1974, 800-802.

(34) Mitschler, A.; Rees, B.; Lehmann, M. S. Electron Density in Bis(dicarbonyl- $\pi$-cyclopentadienyliron) at Liquid Nitrogen Temperature by X-Ray and Neutron Diffraction. J. Am. Chem. Soc. 1978, 100, 3390-3397.

(35) Giannini, L.; SoIari, E.; Angelis, S. D.; Ward, T. R.; Floriani, C.; Chiesi-Villa, A.; Rizzoli, C. Migratory Aptitude of the Zr-C Functionalities Bonded to a Macrocyclic Structure: Thermally- and Solvent-assisted Intra- and Intermolecular Migrations in
Dialkyl(dibenzotetramethyltetraazaannulene)zirconium(IV). J. Am. Chem. Soc. 1995, 117, 5801-5811.

(36) (a) Foster, J. P.; Weinhold, F. Natural hybrid orbitals. J. Am. Chem. Soc. 1980, 102, 7211-7218. (b) Reed, A. E.; Weinhold, F. Natural bond orbital analysis of near-Hartree-Fock water dimer. J. Chem. Phys. 1983, 78, 4066-4073.

(37) (a) Bader, R. F. W. A quantum theory of molecular structure and its applications. Chem. Rev. 1991, 91, 893-928. (b) Bader, R. F. W. Atoms in Molecules. A Quantum Theory (Oxford Univ. Press, Oxford, 1994).

(38) Laidig, K. E.; Bader, R. F. W. Properties of Atoms in Molecules: Atomic Polarizabilities. J. Chem. Phys. 1990, 93, 7213-7224.

(39) Jayarathne, U.; Mazzacano, T. J.; Bagherzadeh, S.; Mankad, N. P. Heterobimetallic Complexes with Polar, Unsupported $\mathrm{Cu}-\mathrm{Fe}$ and $\mathrm{Zn}$-Fe Bonds Stabilized by $N$-Heterocyclic Carbenes. Organometallics 2013, 32, 3986-3992.

(40) (a) Wiberg., K.B. Application of the pople-santry-segal CNDO method to the cyclopropylcarbinyl and cyclobutyl cation and to bicyclobutane. Tetrahedron 1968, 24, 1083-1096. (b) Sizova, O. V.; Skripnikov, L. V.; Sokolov, A. Y. Symmetry decomposition of quantum chemical bond orders, J. Mol. Struct. (Theochem) 2008, 870, 1-3, 1-9.

(41) González-Fabra, J.; Castro-Gómez, F.; Sameera, W. M. C.; Nyman, G.; Kleij, A. W.; Bo, C. Entropic Corrections for the Evaluation of the Catalytic Activity in the Al(III) Catalysed Formation of Cyclic Carbonates from $\mathrm{CO}_{2}$ and Epoxides. Catal. Sci. Technol. 2019, 9, $5433-5440$

(42) Tanaka, R.; Yamashita, M.; Chung, L. W.; Morokuma, K.; Nozaki, K. Mechanistic Studies on the Reversible Hydrogenation of Carbon Dioxide Catalyzed by an Ir-PNP Complex. Organometallics 2011, 30, 6742-6750.

(43) John R. Pinkes; Christopher J. Masi; Robert Chiulli; Bryan D. Steffey; Cutler, A. R. Carbon Dioxide Complexation: Infrared Spectroscopy of Iron and Ruthenium $\eta^{5}$-Cyclopentadienyl Carbonyl Metallocarboxylates. Inorg. Chem. 1997, 36, 70-79.

(44) Castro-Rodriguez, I.; Nakai, H.; Zakharov, L. N.; Rheingold, A. L.; Meyer, K. A linear, O-Coordinated $\eta^{1}-\mathrm{CO}_{2}$ Bound to Uranium. Science 2004, 305, 1757-1759.

(45) Saouma, C. T.; Lu, C. C.; Day, M. W.; Peters, J. C. $\mathrm{CO}_{2}$ reduction by $\mathrm{Fe}(\mathrm{I})$ : solvent control of $\mathrm{C}-\mathrm{O}$ cleavage versus $\mathrm{C}-\mathrm{C}$ coupling Chem. Sci. 2013, 4, 4042-4051.

(46) Falconer, R. L.; Nichol, G.S.; Smolyar, I.V.; Cockroft, S.L.; M.J. Cowley. Reversible Reductive Elimination in Aluminum(II) Dihydrides. Angew. Chem. Int. Ed., 2021, 60, 2047-2052.

(47) (a) Adamo, C.; Barone, V. Toward reliable density functional methods without adjustable parameters: The PBE0 model. J. Chem. Phys. 1999, 110, 6158-6169. (b) Grimme, S.; Ehrlich, S.; Goerigk, L. Effect of the damping function in dispersion corrected density functional theory. J. Comp. Chem. 2011, 32, 1456-1465. (c) Weigend, F.; Ahlrichs, R. Balanced basis sets of split valence, triple zeta valence and quadruple zeta valence quality for $\mathrm{H}$ to $\mathrm{Rn}$ : Design and assessment of accuracy. Phys. Chem. Chem. Phys. 2005, 7, 3297-3305. (d) Marenich, A. V.; Cramer, C. J.; Truhlar, D. G.; Universal solvation model based on solute electron density and a continuum model of the solvent defined by the bulk dielectric constant and atomic surface tensions. J. Phys. Chem. B 2009, 113, 6378-6396.

(48) Gaussian 16, Revision B.01, Frisch, M. J.; Trucks, G. W.; Schlegel, H. B.; Scuseria, G. E.; Robb, M. A.; Cheeseman, J. R.; Scalmani, G.; Barone, V.; Petersson, G. A.; Nakatsuji, H.; Li, X.; Caricato, M.; Marenich, A. V.; Bloino, J.; Janesko, B. G.; Gomperts, R.; Mennucci, B.; Hratchian, H. P.; Ortiz, J. V.; Izmaylov, A. F.; Sonnenberg, J. L.; Williams-Young, D.; Ding, F.; Lipparini, F.; Egidi, F.; Goings, J.; Peng, B.; Petrone, A.; Henderson, T.; Ranasinghe, D.; Zakrzewski, V. G.; Gao, J.; Rega, N.; Zheng, G.; Liang, W.; Hada, M.; Ehara, M.; Toyota, K.; Fukuda, R.; Hasegawa, J.; Ishida, M.; Nakajima, T.; Honda, Y.; Kitao, O.; Nakai, H.; Vreven, T.; Throssell, K.; Montgomery, J. A., Jr.; Peralta, J. E.; Ogliaro, F.; Bearpark, M. J.; Heyd, J. J.; Brothers, E. N.; Kudin, K. N.; Staroverov, V. N.; Keith, T. A.; Kobayashi, R.; Normand, J.; Raghavachari, K.; Rendell, A. P.; Burant, J. C.; Iyengar, S. S.; Tomasi, J.; Cossi, M.; Millam, J. M.; Klene, M.; Adamo, C.; Cammi, R.; Ochterski, J. W.; Martin, R. L.; Morokuma, K.; Farkas, O.; Foresman, J. B.; Fox, D. J. Gaussian, Inc., Wallingford CT, 2016. 
(49) NBO Version 3.1, Glendening, E. D.; Reed, A. E.; Carpenter, J. E.; Weinhold, F.

(50) Lu, T.; Chen, F. Multiwfn: A Multifunctional Wavefunction Analyzer. J. Comput. Chem. 2012, 33, 580-592. 


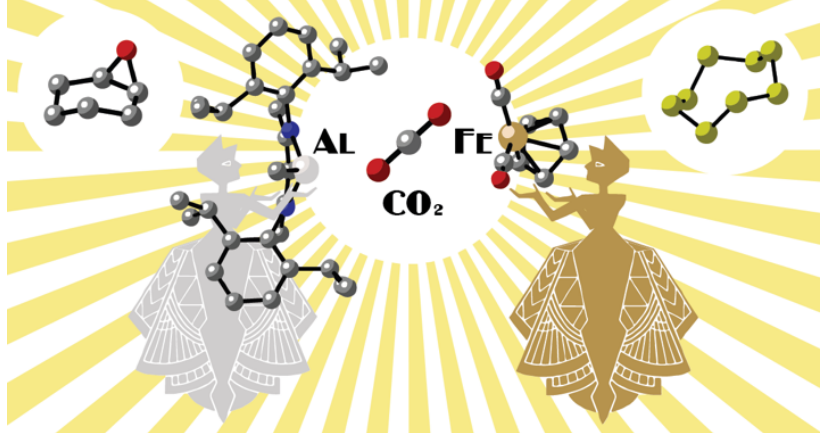

